\title{
Large osteochondral defect in the lateral femoral condyle reconstructed by Atelocollagen-associated autologous chondrocyte implantation combined with anterior cruciate ligament reconstruction
}

\author{
Takuma Kaibara ${ }^{1}$, Eiji Kondo ${ }^{2 *}$, Masatake Matsuoka', Koji Iwasaki ${ }^{3}$, Tomohiro Onodera', Daisuke Momma²,
} Naoki Seito ${ }^{1}$, Susumu Mikami ${ }^{4}$ and Norimasa Iwasaki

\begin{abstract}
Background: Articular surface damage commonly associated with rupture of the anterior cruciate ligament (ACL). Large osteochondral defect, which consists of a severe depression fracture and a large cartilage defect, need to be treated due to deformation of the articular surface as it can impact the clinical outcome of ACL reconstruction. Although autologous chondrocyte implantation is one of the useful options in such cases, it can be questioned whether the reconstruction of the ACL and osteochondral defect should be performed in one procedure alone.

Case presentation: We report a case of a 38-year-old male with a deep depression fracture extending to the edge of the lateral femoral condyle associated with $\mathrm{ACL}$ injury after twisting his right knee while skiing. The patient was successfully treated with tissue-engineered cartilage transplantation covered by the periosteum with an iliac bone graft combined with anatomic double-bundle ACL reconstruction. Histopathological examination of the transplanted cartilage taken at second-look arthroscopy showed a cartilage-like tissue in the middle to deep zone in which the extracellular matrix was largely stained with Safranin O. The patient was able to return to his previous level of skiing activity without any experience of knee pain. Magnetic resonance imaging at 4 years after surgery showed that the graft integrated to the border zone and subchondral bone. The operated knee showed negative Lachman test and had a full range of motion.
\end{abstract}

Conclusions: To our knowledge, this is the first report of anatomic double-bundle ACL reconstruction with tissueengineered cartilage transplantation and an iliac bone graft to restore the lateral edge of the femoral condyle.

Keywords: Osteochondral defect, Autologous chondrocyte implantation, Atelocollagen, Anterior cruciate ligament reconstruction, Orthopedics, Knee

\footnotetext{
* Correspondence: eijik@med.hokudai.ac.jp

${ }^{2}$ Center for Sports Medicine, Hokkaido University Hospital, Kita-15, Nish-7, Kita-ku, Sapporo, Hokkaido 060-8638, Japan

Full list of author information is available at the end of the article
}

C C The Author(s). 2020 Open Access This article is licensed under a Creative Commons Attribution 4.0 International License, which permits use, sharing, adaptation, distribution and reproduction in any medium or format, as long as you give appropriate credit to the original author(s) and the source, provide a link to the Creative Commons licence, and indicate if changes were made. The images or other third party material in this article are included in the article's Creative Commons licence, unless indicated otherwise in a credit line to the material. If material is not included in the article's Creative Commons licence and your intended use is not permitted by statutory regulation or exceeds the permitted use, you will need to obtain permission directly from the copyright holder. To view a copy of this licence, visit http://creativecommons.org/licenses/by/4.0/. The Creative Commons Public Domain Dedication waiver (http://creativecommons.org/publicdomain/zero/1.0/) applies to the data made available in this article, unless otherwise stated in a credit line to the data. 


\section{Background}

The lateral femoral notch sign was first described by Loose et al. as a small depression fracture in the lateral femoral condyle associated with an anterior cruciate ligament (ACL) injury [1]. It is caused by an impression fracture of the lateral femoral condyle at the time of injury in $25 \%$ of patients [2]. Although the lateral femoral notch sign usually has only radiographic finding without the need for any surgical intervention, the severe depression fracture has clinical importance due to articular surface deformity of the femoral condyle as it can affect the clinical outcome of ACL reconstruction. However, there are several issues in such cases, we must be concerned with such as surgical strategies, options and the timing of ACL reconstruction [3-6].

A variety of surgical procedures have been developed to repair the articular surface of the knee. Treatment options for osteochondral defects of the knee include abrasion chondroplasty [7], debridement [8], drilling or microfracture [9], allograft transplantation [10], periosteal transplantation [11], and autograft transplantation [12]. Autologous chondrocyte implantation (ACI) was introduced in 1994 for the treatment of articular cartilage injuries [13] and favorable outcomes were continuously reported [14-16]. Recently, matrix-induced autologous chondrocyte implantation (MACI) that utilized the collagen carrier membrane has been attracting attention, especially for the large osteochondral lesion. Atelocollagen-associated ACI, one MACI technique, is a newly developed tissue-engineering approach for constructing a tissue-engineered cartilage in a threedimensional culture using atelocollagen gel [17]. This technique is widely proposed as one option for the restoring osteochondral defect of the knee $[18,19]$. However, it can be questioned whether the ACL reconstruction and the MACI procedure should be performed in one overall procedure.

Several issues need to be considered when making treatment decision for a full-thickness cartilage defect with an ACL injured knee. Only a few studies have described a combined treatment of osteochondral defects with ACL injured knee using autologous osteochondral grafting, autologous periosteum, periosteum-covered ACI, or MACI [20-23]. Although a combined treatment using ACI with ACL reconstruction seems to be one of the most useful options, there has been no previous report about a case of ACL injured knee with a huge depression fracture extending to the lateral wall of the femoral condyle.

Recently, we encountered a case of ACL injury with a huge depression fracture extending to lateral wall in the lateral femoral condyle. We treated the patient by using a transplantation method of tissue-engineered cartilage which used scaffold composed of atelocollagen gel matrix covered by the periosteum with an iliac bone graft combined with anatomic double-bundle ACL reconstruction. To our knowledge, this is the first report of ACL reconstruction with MACI implantation and iliac bone graft to reconstruct the lateral edge of the femoral condyle.

\section{Case presentation}

A 38-year-old male sustained an injury to his right knee while skiing. The patient experienced a twisting of his knee, while a valgus impaction force was applied to the slightly flexed knee. The patient had a dislocated feeling in his knee with severe knee pain and could not stand up. He visited our affiliate hospital on the day of the accident. Physical examination revealed knee effusion and a positive Lachman test with valgus instability in right knee. The patient presented the tenderness at the medial collateral ligament (MCL) and the lateral femoral condyle. The range of motion was reduced to 90 degrees of flexion due to knee pain. Fat droplets were present in the aspirated blood from the knee joint. Plain radiographs showed a huge depression fracture in the lateral femoral condyle (Fig. 1a, b). Computed tomography (CT) also revealed a huge depressed lesion of $35 \mathrm{~mm} \times$ $15 \mathrm{~mm}$ in area and $7 \mathrm{~mm}$ in depth in the joint surface of the lateral femoral condyle extending to the edge of the condyle (Fig. 1c). Magnetic resonance imaging (MRI) showed an ACL and superficial MCL tears combined with a huge depression fracture in the injured knee (Fig. 1d, e).

Four weeks after injury, arthroscopy was performed at the same hospital. The arthroscopy revealed that the patient had an ACL rupture, a large cartilage injury, and a huge depression fracture on the lateral femoral condyle. Superficial MCL was repaired with a suture anchor. Eight weeks after injury, this patient was referred to our hospital. We decided a two-staged surgery which was ACL reconstruction with MACI implantation and an iliac bone graft. First, we conducted an arthroscopically assisted cartilage harvest for MACI procedure from the medial edge of the femoral trochlea of the ipsilateral knee joint [17]. Briefly, under general anesthesia, approximately $800 \mathrm{mg}$ of cartilage tissue was harvested. The cartilage tissue was sent to the facility (Japan Tissue Engineering Co., Ltd., Gamagori, Japan). Chondrocytes were isolated from the obtained cartilage specimen and one volume of isolated chondrocytes was suspended into four volumes of atelocollagen solution (3\% type I collagen; Koken, Tokyo, Japan). The mixture was put on culture flasks and gelated entirely by incubation at $37^{\circ} \mathrm{C}$. The tissue-engineered cartilage was then cultured in a three-dimension manner in an atmosphere of $5 \%$ carbon dioxide and $95 \%$ air at $37^{\circ} \mathrm{C}$ for four weeks. The 


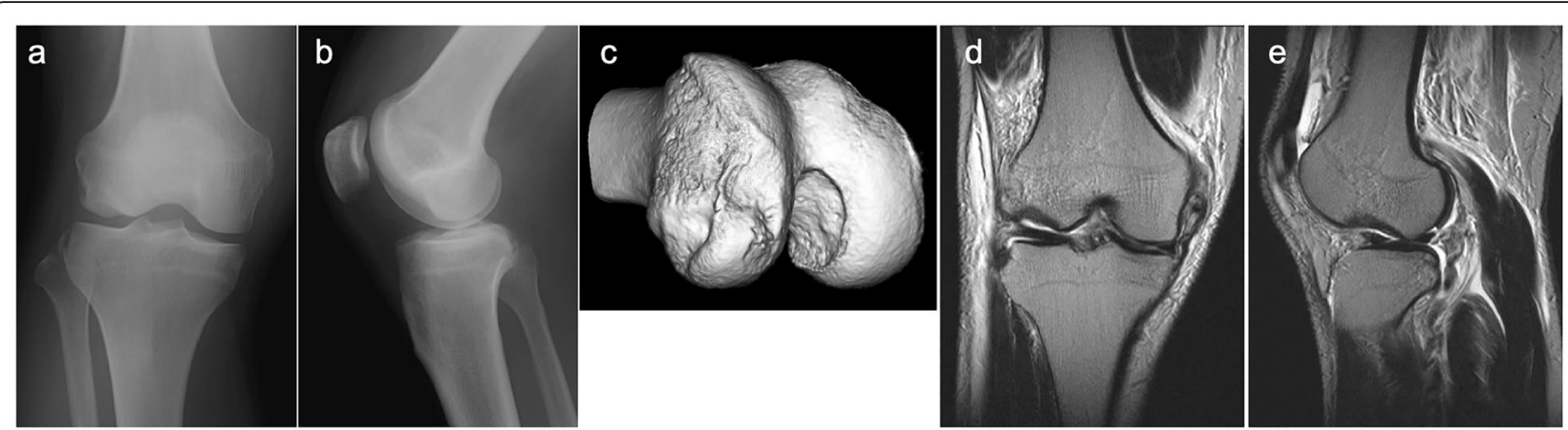

Fig. 1 X-ray, computed tomography scan and magnetic resonance imaging before surgery. a Anteroposterior, b Lateral radiographs, c A 3dimensional computed tomography of the right knee demonstrating a large depression fracture of the lateral femoral condyle. $\mathbf{d}$ Coronal T2weighted, e Sagittal T2-weighted magnetic resonance imaging of the right knee taken before surgery demonstrated a large osteochondral defect of the lateral femoral condyle and superficial medial collateral ligament rupture

cultured cartilage had become a jelly-like form with the progress of cultivation [17-19].

Four weeks after harvest of the cartilage tissue, we carried out a second surgery. Under general anesthesia, the patient was placed in a supine position on the operating room table. First, an arthroscopic anatomic doublebundle ACL reconstruction with a hamstring tendon autograft was performed using the transtibial tunnel technique according to previous study [24]. The harvested ipsilateral semitendinosus tendon was halved and doubled over for graft preparation. A Leeds-Keio Artificial Ligament (Neoligament, Leeds, England) was mechanically connected at an unlooped end of the folded tendon $[25,26]$. Then, an Endobutton CL BTB (Smith \& Nephew, Andover, MA) was tied at the looped end [27].

Second, the osteochondral defect and depression fracture of the lateral femoral condyle were exposed through the lateral parapatellar approach. The size of osteochondral defect was approximately $20 \times 30 \mathrm{~mm}$ (Fig. 2a). The osteochondral lesion was debrided to expose the underlying subchondral plate. Bi-cortical bone block harvested from the right iliac crest was trimmed to reconstruct the normal shape of the lateral femoral condyle. The harvested bone block was fixed to the lateral edge of the lateral femoral condyle with three Poly-L-Lactic Acid pins (PL-Fix, Zimmer Biomet, Warsaw, IN) (Fig. 2b). The iliac periosteal flap was loosely sutured to the adjacent rim of the healthy cartilage with a polyester thread using a pullout technique (Fig. 2c). After half the border of the periosteal flap was sutured, tissue-engineered cartilage covered by atelocollagen gel matrix was placed in the cartilage defect region, then the remaining half of the flap was sutured with a polyester thread and 5-0 nylon (Fig. 2d).

Finally, the graft for the PL bundle was placed through the PL tibial tunnel to the femoral tunnel with a passing pin. The graft for the AM bundle was introduced in the same way and fixed with $30 \mathrm{~N}$ tension to each graft using tensiometers (Yufu Itonaga Co., Ltd., Tokyo, Japan) at $10^{\circ}$ of knee flexion. The 2 tape portions onto the tibia were secured using two spiked staples (Smith \& Nephew) in the turn-buckle fashion. The operation time was 231 min.

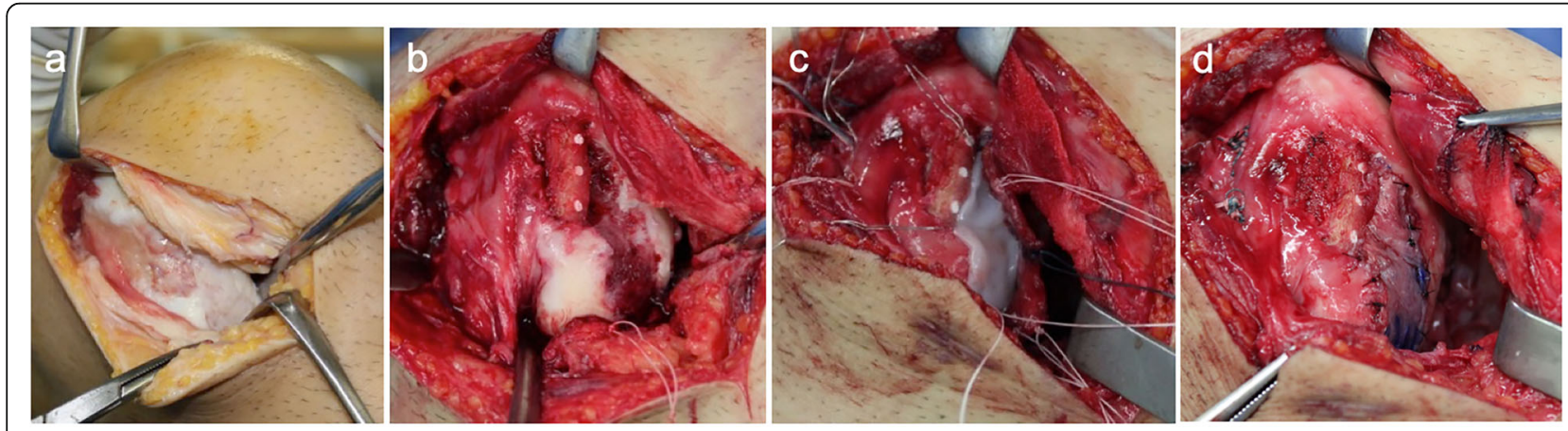

Fig. 2 Surgical procedure for the large depressed fracture of the lateral femoral condyle. a The picture showing an extensive depressed osteochondral fracture on the lateral femoral condyle (approximately $20 \times 30 \mathrm{~mm}$ ). b After debridement and curettage of the lesion, an iliac cortical bone graft was fixed with three Poly-L-Lactic Acid pins. c Chondrocytes-atelocollagen gel was put on the defect area. $d$ Iliac periosteum was sutured with 5-0 nylons to the surrounding rim 
After 2 weeks of the knee joint immobilization, continuous passive motion exercise of the knee joint was allowed. Partial weight-bearing was started at 6 weeks, and full weight-bearing was allowed from 8 weeks. A functional knee brace was used for a period of 3 months. CT scan taken 12 months after the 2nd surgery showed that the contour of the lateral femoral condyle was reconstructed with the implanted iliac bone graft (Fig. 3a). Thirteen months later, second-look arthroscopy and staple removal were performed. Second-look arthroscopy showed that the depressed area was covered with smooth cartilaginous tissue with a native cartilage-like hardness (Fig. 3b). ACL graft had no laceration and an excellent coverage of synovium (Fig. 3c). A needle biopsy was taken from the center of the grafted cartilage. The grafted cartilage histologically composed of fibrous tissue in the smooth superficial layer and cartilage-like tissue in the middle to deep layer where the extracellular matrix was strongly stained with Safranin O (Fig. 4). Implanted tissue had no vascularization and integrated into subchondral bone. The morphology of cells in the middle to deep layer were oval with a pericellular lacuna.

Sports activities were allowed at 18 months after surgery, and he was able to ski once again. The patient returned to his previous skiing activity level without any knee pain. After 4 years, MRI showed that the graft was incorporated into the border zone and the subchondral bone (Fig. 5). After a final follow-up, the knee showed a negative Lachman test, a negative pivot-shift test, and had a full range of knee motion. The side-to-side difference in the anterior laxity at 30 degrees of knee flexion measured with KT-2000 was $2.0 \mathrm{~mm}$. Lysholm knee score was 94 points. The objective International Knee Documentation Committee (IKDC) was determined as grade A. Knee injury and Osteoarthritis Outcome Score
(KOOS) was 82.1, 94.4, 100.0, 50.0, and 68.8 in Pain, other Symptoms, Function in daily living (ADL), Function in Sport and Recreation (Sport/Rec), and kneerelated Quality of Life (QOL), respectively.

\section{Discussion}

We reported a case with a large cartilage defect and deep depression fracture in the femoral condyle extending to the lateral edge associated with acute ACL injury. Because the lateral femoral condyle could not be reconstructed by transplanting a tissue-engineered cartilage, the bi-cortical bone block and the iliac periosteum from the iliac crest was applied to achieve the anatomical contour of the lateral femoral condyle.

There were several key issues in this case. As for ACL reconstruction, we believe that the anatomic doublebundle technique was the best way to restore normal knee function [24, 28], although the clinical utility of anatomic double-bundle reconstruction in comparison with the conventional single-bundle reconstruction remains controversial [29]. In the current case, we performed anatomic double-bundle procedure, lateral wall reconstruction, and MACI implantation in the lateral femoral condyle simultaneously to avoid the ACI graft failure due to the knee joint instability. As for depression fracture in the lateral femoral condyle, the transplantation of iliac cortical bone was needed to reconstruct a normal contour of the lateral wall because the lateral femoral condyle was severely depressed at the time of injury. This type of operation offers several advantages such as enhanced articular cartilage repair, early discharge and a daily and sports-related activities although it might require a longer operation time resulting in an increased invasiveness to the knee. Therefore, the

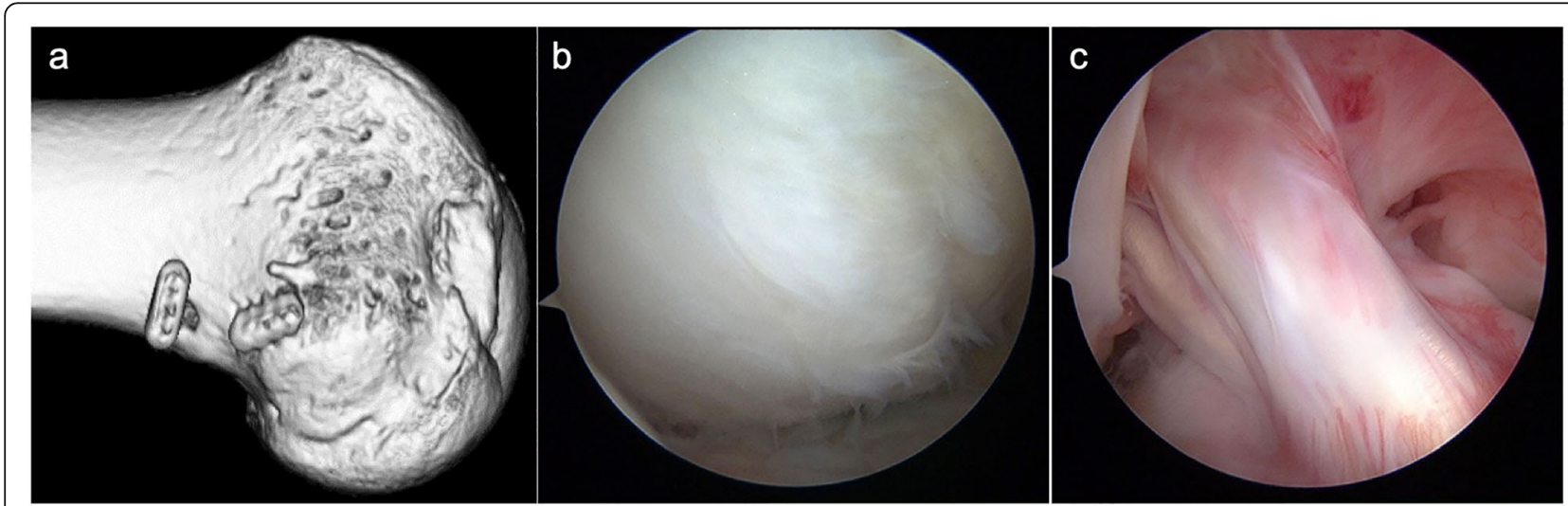

Fig. 3 Postoperative imaging of computed tomography and second-look arthroscopic appearance. A 3-dimensional computed tomography of the lateral femoral condyle from a lateral side view at 13 months after surgery. a Postoperative image showed the contour of the lateral femoral condyle was reconstructed with the implanted iliac bone graft. b Smooth cartilaginous tissue with a slightly fibrillated surface was observed at the implantation site of the lateral femoral condyle. c Reconstructed anterior cruciate ligament grafts had no laceration or elongation and was wholly covered with synovium 


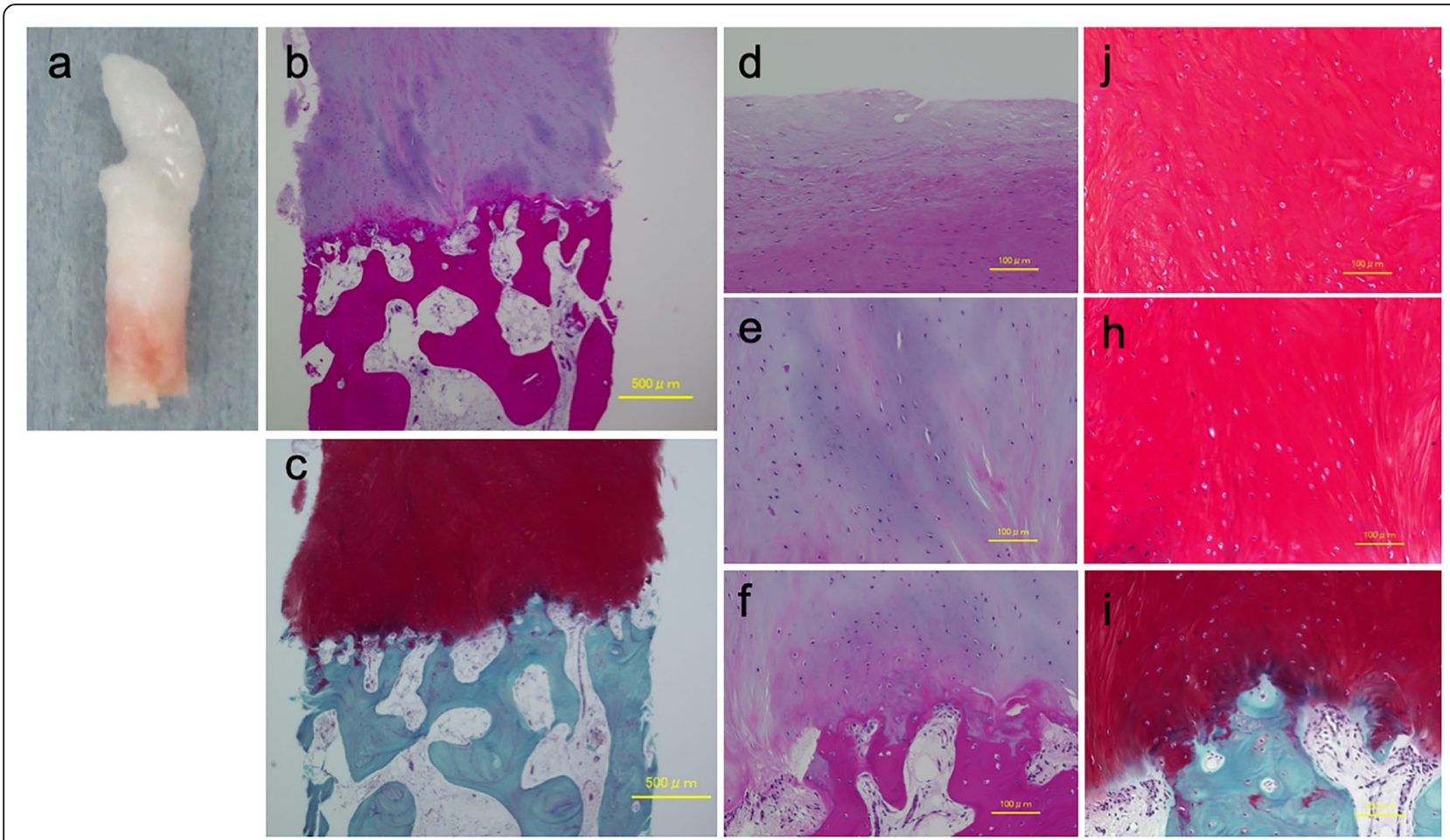

Fig. 4 Histopathological findings of graft tissue taken by biopsy at 13 months postoperatively. a Gross view of the graft tissue showing cartilagenous tissue. Hematoxylin and eosin (b, d-f) and Safranin-O stain $(\mathbf{c}, \mathbf{j}-\mathbf{i})$ at $4 \times$ magnification $(\mathbf{b}, \mathbf{c})$ and $10 \times$ magnification $(\mathbf{d}-\mathbf{i})$. Grafted tissue consisted of fibrous tissue in the superficial layer (d) and cartilage-like tissue in the middle to deep layer (e, $\mathbf{f}$ ) in which the extracellular matrix was stained with Safranin $\mathrm{O}(\mathbf{c}, \mathbf{j} \mathbf{- i})$. Histologically, grafted tissue was well bonded to the subchondral bone $(\mathbf{f}$, $\mathbf{i}$ ), but the normal layer composition was not observed

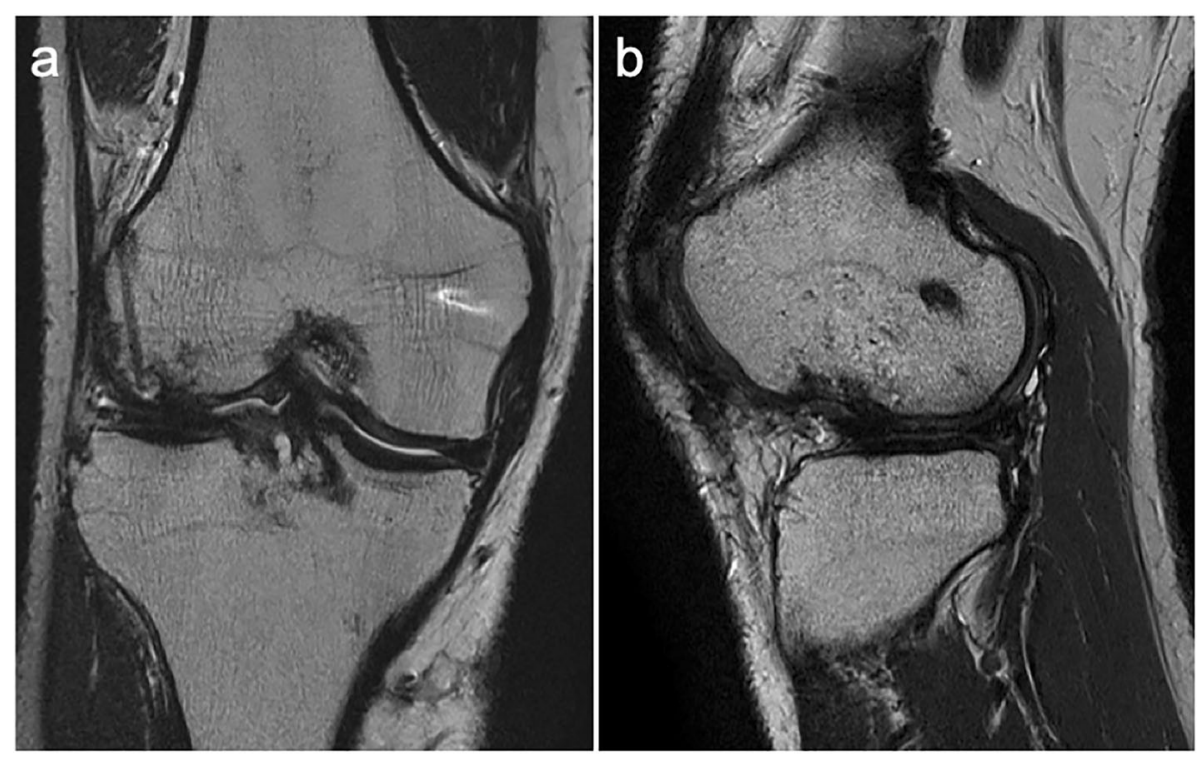

Fig. 5 Magnetic resonance imaging (MRI) evaluation at 4 years after surgery. a Coronal T2-weighted, b Sagittal T2-weighted MRI images of the right knee demonstrating integration of graft tissue to border zone and subchondral bone 
surgeon needs not only technical skill but also must proceed in a step by step process.

Various type of ACI have been investigated for the treatment for osteochondral defects of the knee [30, 31]. Atelocollagen-associated ACI utilized atelocollagen as a matrix for the three-dimensional expansion and embedding of harvested cartilage [17]. Previous study reported that human chondrocytes can proliferate and synthesize the extracellular matrix without changing their phenotype in atelocollagen gel for 4 weeks [32]. Several clinical trials have confirmed the efficacy of atelocollagenassociated ACI $[18,19,33]$. This atelocollagenassociated ACI procedure is the only ACI procedure which has been approved by the Japanese Health Insurance since 2013. In current case, the histology revealed that the repaired tissue consisted of a hyaline-like cartilage with a rich extracellular matrix although the zonal arrangement of the repaired tissue were not completely well-organized.

Amin et al. compared the clinical results of ACI in combination with ACL reconstruction to $\mathrm{ACI}$ following previous ACL reconstruction in their patients and concluded that the treatment of ACI in combination with ACL reconstruction was technically achievable, with good to excellent outcomes over a short time period [20]. Dhinsa et al. reported that ACI in combination with ACL reconstruction is a feasible option with similar results as those patients who have had the procedures staged and prioritized a combined strategy in terms of cost and a short rehabilitation period [21]. Pike et al. reported improved clinical outcomes of eighteen out of twenty-six patients with concurrent $\mathrm{ACI}$ and either primary or revision ACL reconstruction with a mean follow-up of 7 years and concluded that ACI can contribute to moderately improved pain and function during a long-term follow-up [23]. Adachi et al. reported an osteochondral lesion $(15 \times 15 \mathrm{~mm})$ on the lateral femoral condyle reconstructed by the transplantation of tissueengineered cartilage combined with an iliac bone graft [34]. We referred to this technique. Based on these studies, in case of an ACL injured knee with a large cartilage defect and a huge depression fracture extending to the lateral wall, a surgical plan should be discussed for each case in advance whether it be a one-staged or a twostaged procedure.

There are several limitations in this report. First, a limitation of this ACI procedure is that a restricted number of autologous chondrocytes can be obtained from any one patient. A second disadvantage is that a 2stage operation is required. Moreover, arthrotomy has to be performed for second implantation, and this is an invasive procedure, although the ideal chondrocyte implantation procedure is still controversial. The third limitation is the regenerated tissue after our procedure.
Because the histological evaluations demonstrated that the regenerated tissues were not true hyaline cartilage and that columnar distribution of the normal cartilage was not established, there is a possibility that longer follow-up would show that the regenerated tissue deteriorates.

In conclusion, although future studies are needed to investigate the reproducibility of our surgical strategy, simultaneous cartilage repair with atelocollagenassociated ACI and lateral wall reconstruction with an iliac bone graft for femoral large bony defect combined with ACL reconstruction had favorable four-year outcomes.

\section{Abbreviations}

ACL: Anterior cruciate ligament; ACl: Autologous chondrocyte implantation; CT: Computed tomography; MCL: Medial collateral ligament; MRI: Magnetic resonance imaging; AM: Anterior-medial; PL: Postero-lateral

\section{Acknowledgements}

Special thanks to Toshiaki Kameda for his advice and expertise.

\section{Authors' contributions}

EK was involved in the design of the study, performed the clinical assessment, analysis and interpretation of data, and drafted and revised the manuscript. TK and MM were involved in the design of the study, assisted with data interpretation, and revised the manuscript for important intellectual content. KI, TO, DM, NS, SM, and NI were involved in the design of the study and the data acquisition and revised the manuscript critically for important intellectual content. All authors have read and approved the final manuscript.

\section{Funding}

No specific funding was received from any funding bodies in the public, commercial or not-for profit to carry out the work described in this article.

\section{Availability of data and materials}

This is a case report of a single patient, in order to protect privacy and respect confidentiality; none of the raw data has been made available in any public repository. The original operation reports, intraoperative photographs, imaging studies and outpatient clinical records are retained as per normal procedure among the medical records of our institution. All data concerning the case are presented in the manuscript.

Ethics approval and consent to participate

Written informed consent was obtained from the patient for publication of this case report.

\section{Consent for publication}

Written informed consent was obtained from the patient for publication of this case report and any accompanying images.

\section{Competing interests}

The authors declare that they have no competing interests.

\section{Author details}

${ }^{1}$ Department of Orthopaedic Surgery, Hokkaido University Graduate School of Medicine, Kita-15, Nish-7, Kita-ku, Sapporo, Hokkaido 060-8638, Japan. ${ }^{2}$ Center for Sports Medicine, Hokkaido University Hospital, Kita-15, Nish-7, Kita-ku, Sapporo, Hokkaido 060-8638, Japan. ${ }^{3}$ Department of functional reconstruction for the knee joint, Hokkaido University, Kita-15, Nish-7, Kita-ku, Sapporo, Hokkaido 060-8638, Japan. ${ }^{4}$ Department of Orthopaedic Surgery, Hokkaido Orthopaedic Memorial Hospital, 5-22, 7-Jo 13-Chome, Hiragishi, Toyohira-ku, Sapporo, Hokkaido 062-0937, Japan. 
Received: 13 April 2020 Accepted: 21 July 2020

Published online: 27 July 2020

\section{References}

1. Losee RE, Johnson TR, Southwick WO. Anterior subluxation of the lateral tibial plateau. A diagnostic test and operative repair. J Bone Joint Surg Am. 1978:60(8):1015-30.

2. Herbst E, Hoser C, Tecklenburg K, Filipovic M, Dallapozza C, Herbort M, Fink C. The lateral femoral notch sign following $A C L$ injury: frequency, morphology and relation to meniscal injury and sports activity. Knee Surg Sports Traumatol Arthrosc. 2015;23(8):2250-8.

3. Garth WP Jr, Wilson T. Open reduction of a lateral femoral notch associated with an acute anterior cruciate ligament tear. Arthroscopy. 2001;17(8):874-7.

4. Sadlo PA, Nebelung W. Arthroscopically assisted reduction of a lateral femoral notch in acute tear of the anterior cruciate ligament. Arthroscopy. 2006;22(5):574 e571-3.

5. Tauber M, Fox M, Koller H, Klampfer $\mathrm{H}$, Resch $\mathrm{H}$. Arthroscopic treatment of a large lateral femoral notch in acute anterior cruciate ligament tear. Arch Orthop Trauma Surg. 2008;128(11):1313-6.

6. Matsuoka M, Inoue M, Shimamoto N, Iwasaki N, Yasuda K. Two-staged arthroscopy-assisted treatment of a large depression fracture in the lateral femoral condyle associated with an acute anterior cruciate ligament tear. Eur Orthop Traumatol. 2015;6(1):55-60.

7. Jomha NM, Borton DC, Clingeleffer AJ, Pinczewski LA. Long-term osteoarthritic changes in anterior cruciate ligament reconstructed knees. Clin Orthop Relat Res. 1999:358:188-93.

8. Sprague NF. 3rd: Arthroscopic debridement for degenerative knee joint disease. Clin Orthop Relat Res. 1981;160:118-23.

9. Steadman JR, Rodkey WG, Rodrigo JJ. Microfracture: surgical technique and rehabilitation to treat chondral defects. Clin Orthop Relat Res. 2001;391: S362-9.

10. Bugbee WD. Fresh osteochondral allografts. J Knee Surg. 2002;15(3):191-5.

11. O'Driscoll SW, Keeley FW, Salter RB. Durability of regenerated articular cartilage produced by free autogenous periosteal grafts in major fullthickness defects in joint surfaces under the influence of continuous passive motion. A follow-up report at one year. J Bone Joint Surg Am. 1988;70(4): 595-606.

12. Johnson DL, Urban WP Jr, Caborn DN, Vanarthos WJ, Carlson CS. Articular cartilage changes seen with magnetic resonance imaging-detected bone bruises associated with acute anterior cruciate ligament rupture. Am J Sports Med. 1998;26(3):409-14.

13. Brittberg M, Lindahl A, Nilsson A, Ohlsson C, Isaksson O, Peterson L. Treatment of deep cartilage defects in the knee with autologous chondrocyte transplantation. N Engl J Med. 1994;331(14):889-95.

14. Peterson L, Minas T, Brittberg M, Nilsson A, Sjogren-Jansson E, Lindahl A. Two- to 9-year outcome after autologous chondrocyte transplantation of the knee. Clin Orthop Relat Res. 2000;374:212-34.

15. Knutsen G, Engebretsen L, Ludvigsen TC, Drogset JO, Grontvedt T, Solheim E, Strand T, Roberts S, Isaksen V, Johansen O. Autologous chondrocyte implantation compared with microfracture in the knee. A randomized trial. J Bone Joint Surg Am. 2004;86-A(3):455-64.

16. Jakobsen RB, Engebretsen $L$, Slauterbeck JR. An analysis of the quality of cartilage repair studies. J Bone Joint Surg Am. 2005;87(10):2232-9.

17. Ochi M, Uchio Y, Kawasaki K, Wakitani S, Iwasa J. Transplantation of cartilage-like tissue made by tissue engineering in the treatment of cartilage defects of the knee. J Bone Joint Surg (Br). 2002;84(4):571-8.

18. Adachi N, Ochi M, Deie M, Nakamae A, Kamei G, Uchio Y, Iwasa J. Implantation of tissue-engineered cartilage-like tissue for the treatment for full-thickness cartilage defects of the knee. Knee Surg Sports Traumatol Arthrosc. 2014:22(6):1241-8.

19. Tohyama H, Yasuda K, Minami A, Majima T, Iwasaki N, Muneta T, Sekiya I, Yagishita K, Takahashi S, Kurokouchi K, et al. Atelocollagen-associated autologous chondrocyte implantation for the repair of chondral defects of the knee: a prospective multicenter clinical trial in Japan. J Orthop Sci. 2009; 14(5):579-88.

20. Amin AA, Bartlett W, Gooding CR, Sood M, Skinner JA, Carrington RW Briggs TW, Bentley G. The use of autologous chondrocyte implantation following and combined with anterior cruciate ligament reconstruction. Int Orthop. 2006;30(1):48-53.
21. Dhinsa BS, Nawaz SZ, Gallagher KR, Skinner J, Briggs T, Bentley G. Outcome of combined autologous chondrocyte implantation and anterior cruciate ligament reconstruction. Indian J Orthop. 2015;49(2):155-63.

22. Peterson L, Vasiliadis HS, Brittberg M, Lindahl A. Autologous chondrocyte implantation: a long-term follow-up. Am J Sports Med. 2010;38(6):1117-24.

23. Pike AN, Bryant T, Ogura T, Minas T. Intermediate- to long-term results of combined anterior cruciate ligament reconstruction and autologous chondrocyte implantation. Orthop J Sports Med. 2017;5(2): 2325967117693591

24. Yasuda K, Kondo E, Ichiyama H, Kitamura N, Tanabe $Y$, Tohyama H, Minami A. Anatomic reconstruction of the anteromedial and posterolateral bundles of the anterior cruciate ligament using hamstring tendon grafts. Arthroscopy. 2004;20(10):1015-25.

25. Kondo E, Yasuda K, Miyatake S, Kitamura N, Tohyama H, Yagi T. Clinical comparison of two suspensory fixation devices for anatomic double-bundle anterior cruciate ligament reconstruction. Knee Surg Sports Traumatol Arthrosc. 2012;20(7):1261-7.

26. Inagaki Y, Kondo E, Kitamura N, Onodera J, Yagi T, Tanaka Y, Yasuda K. Prospective clinical comparisons of semitendinosus versus semitendinosus and gracilis tendon autografts for anatomic double-bundle anterior cruciate ligament reconstruction. J Orthop Sci. 2013;18(5):754-61.

27. Miyatake S, Kondo E, Tohyama H, Kitamura N, Yasuda K. Biomechanical evaluation of a novel application of a fixation device for bone-tendon-bone graft (EndoButton CL BTB) to soft-tissue grafts in anatomic double-bundle anterior cruciate ligament reconstruction. Arthroscopy. 2010;26(9):1226-32.

28. Kondo $\mathrm{E}$, Yasuda $\mathrm{K}$, Azuma $\mathrm{H}$, Tanabe Y, Yagi T. Prospective clinical comparisons of anatomic double-bundle versus single-bundle anterior cruciate ligament reconstruction procedures in 328 consecutive patients. Am J Sports Med. 2008;36(9):1675-87.

29. Yasuda K, Tanabe Y, Kondo E, Kitamura N, Tohyama H. Anatomic doublebundle anterior cruciate ligament reconstruction. Arthroscopy. 2010;26(9 Suppl):S21-34.

30. Samsudin EZ, Kamarul T. The comparison between the different generations of autologous chondrocyte implantation with other treatment modalities: a systematic review of clinical trials. Knee Surg Sports Traumatol Arthrosc. 2016;24(12):3912-26.

31. Vasiliadis HS, Wasiak J, Salanti G. Autologous chondrocyte implantation for the treatment of cartilage lesions of the knee: a systematic review of randomized studies. Knee Surg Sports Traumatol Arthrosc. 2010;18(12): 1645-55.

32. Uchio $Y$, Ochi M, Matsusaki M, Kurioka H, Katsube K. Human chondrocyte proliferation and matrix synthesis cultured in Atelocollagen gel. J Biomed Mater Res. 2000;50(2):138-43.

33. Takazawa K, Adachi N, Deie M, Kamei G, Uchio Y, Iwasa J, Kumahashi N, Tadenuma T, Kuwata S, Yasuda K, et al. Evaluation of magnetic resonance imaging and clinical outcome after tissue-engineered cartilage implantation: prospective 6-year follow-up study. J Orthop Sci. 2012;17(4):413-24.

34. Adachi N, Ochi M, Uchio Y, Iwasa J, Furukawa S, Deie M. Osteochondral lesion located at the lateral femoral condyle reconstructed by the transplantation of tissue-engineered cartilage in combination with a periosteum with bone block: a case report. Knee Surg Sports Traumatol Arthrosc. 2004;12(5):444-7.

\section{Publisher's Note}

Springer Nature remains neutral with regard to jurisdictional claims in published maps and institutional affiliations.

Ready to submit your research? Choose BMC and benefit from:

- fast, convenient online submission

- thorough peer review by experienced researchers in your field

- rapid publication on acceptance

- support for research data, including large and complex data types

- gold Open Access which fosters wider collaboration and increased citations

- maximum visibility for your research: over $100 \mathrm{M}$ website views per year

At BMC, research is always in progress.

Learn more biomedcentral.com/submission 